\title{
Nuevas respuestas a partir de la reconstrucción virtual de una urna cerámica del complejo cultural El Vergel, Chile
}

New Answers Based on the Virtual Reconstruction of a Ceramic Urn in El Vergel Cultural Complex, Chile

\author{
Natalia Andrea Naranjo Mogollones \\ Laboratorio de Arqueología, \\ Centro Nacional de Conservación y Restauración (CNCR), Chile \\ natalia.naranjo@cncr.cl
}

\begin{abstract}
Antonio Suazo Navia
Unidad de Documentación Visual e Imagenología,

Centro Nacional de Conservación y Restauración (CNCR), Chile

documentacion.4@cncr.cl
\end{abstract}

\section{Resumen}

En este REPORTE se presenta el caso de estudio de una urna cerámica sin contexto atribuida al complejo cultural El Vergel, adscrita al periodo Alfarero tardío (Región de la Araucanía, Chile). Sus principales problemas de alteración se relacionan con sus faltantes, su gran formato y el descalce de sus fragmentos. Para resolverlos, la reconstrucción virtual se realizó en Blender $\Re_{\text {, a partir de }}$ un modelo generado por fotogrametría digital mediante la cual se realizaron análisis morfológicos y se proyectaron las intervenciones. Como resultado, se estableció un estado inicial proyectado, previo a la fragmentación, que permitió disponer de la urna para su análisis como objeto unitario y atender así los desafíos ligados tanto al estudio desde la perspectiva arqueológica como a la conservación, el almacenamiento y sus eventuales intervenciones.

\section{Palabras clave}

Cerámica arqueológica; cerámica fragmentada; fotogrametría; restauración virtual; El Vergel; Chile

\section{Abstract}

This REPORT presents the case study of a ceramic urn (without any archaeological context) attributed to the cultural complex El Vergel, and indicated to be from the Late Pottery period (Region of Araucanía, Chile). The main alteration problems of this piece relate to its missing parts, large format, and mismatch of fragments. To solve these issues, a virtual reconstruction was done using Blender ${ }^{\circledR}$, based on a model generated by digital photogrammetry through which morphological analyses were carried out and interventions were projected. As a result, an initial projected state, 
prior to the fragmentation, was established. This allowed the urn to be available for its analysis as a unitary object and thus address the challenges linked, from an archeological perspective, to both its study and its storage and eventual interventions.

\section{Keywords}

archaeological ceramic; fragmented ceramic; photogrammetry; virtual restoration; El Vergel; Chile

\section{Introducción}

a técnica de digitalización por fotogrametría permite la adquisición de modelos tridimensionales por medios no invasivos, incluida la obtención de color. Es útil para la documentación debido a su bajo costo, gran resolución de captura, registro de la información de color de la superficie del objeto de estudio e inmediatez, y, en general, constituye un nuevo método complementario para los estudios objetuales y contextuales del patrimonio (Sánchez 2014; Correa et al. 2016; Garstki 2017; Stancco et al. 2011).

En el año 2006 el Centro Nacional de Conservación y Restauración (CNCR) intervino por primera vez urnas funerarias provienentes del Museo Regional de la Araucanía (Temuco, Región de la Araucanía, Chile), en el marco de la renovación museográfica de dicha institución. Desde esa perspectiva, se desea presentar un caso de estudio de una urna cerámica descontextualizada, la cual posee una zona importante de faltantes estructurales y un alto grado de fragmentación, desafíos presentes al momento de establecer los procesos de intervención de la pieza, que fue posible definir con base en la denominada reconstrucción virtual (IFVA 2012), utilizando la digitalización por fotogrametría.

En respuesta a los retos mencionados, en las siguientes líneas se expone el uso del modelado tridimensional como una técnica para documentar bienes culturales muebles e inmuebles, como recurso del cual se obtienen datos útiles para los restauradores, ya que aporta nueva información para la conservación y genera conocimientos valiosos para disciplinas afines, como la arqueología. Estos nuevos datos contribuyeron a determinar las características objetuales de la pieza, así como proyectar sus eventuales restauraciones, las cuales fueron relevantes al momento de evaluar los procesos de intervención sobre la urna.

\section{Caso de estudio para el Laboratorio de Arqueología y la Unidad de Documentación Visual e Imagenología del Centro Nacional de Conservación y Restauración, Chile}

El CNCR (Centro Nacional de Conservación y Restauración, Chile) es una institución perteneciente al Servicio
Nacional del Patrimonio Cultural, dependiente del Ministerio de las Culturas, las Artes y el Patrimonio, por lo que sus recursos son de carácter público. Entre sus dependencias se encuentra el Laboratorio de Arqueología, el cual busca promover la preservación integral del patrimonio arqueológico de Chile.

Asociada con las diferentes dependencias del CNCR, la Unidad de Documentación Visual e Imagenología se encarga, por su parte, de obtener la información visual de los bienes culturales durante los procesos de estudio, diagnóstico e intervención en conservación y restauración.

Dentro de las líneas de trabajo vinculadas con la intervención e investigación del patrimonio arqueológico, ingresó en el Laboratorio de Arqueología del CNCR un conjunto de urnas cerámicas fragmentadas de gran formato procedentes del Museo Regional de la Araucanía (para mayor información, véase Anón. 2009), ubicado al sur del país.

De la serie de fragmentos se identificaron 16 partes pertenecientes a una pieza sin número de inventario de grandes dimensiones (Figura 1), sin diseños iconográficos en su superficie y con evidencia de perforaciones intencionales de origen prehispánico. En estos agujeros se introducían cuerdas con el fin de sujetar las secciones de la cerámica durante su reparación cuando ésta sufría fracturas originadas en el proceso de manufactura o a causa de su uso en los contextos domésticos, donde se empleaban como contenedores de gran formato y luego se designaban para ritos funerarios (cfr. Adán et al. 2016).

Dentro de los principales problemas de alteración de la vasija se reconocieron su fragmentación y los faltantes, especialmente del cuerpo y cuello, donde, además, las porciones remanentes no calzaban o bien carecían de puntos de apoyo para su ubicación (Figura 2).

La información contextual de la urna es casi inexistente, ya que sólo se conoce que se recuperó de la comuna de Nueva Imperial de la Región de la Araucanía (Anón. 2008: 127) (Figura 3). Esto último es relevante debido a que la zona es conocida por poseer hallazgos de urnas funerarias del complejo cultural El Vergel del periodo Alfarero tardío, situado entre el 1000 d.C. y el 1300 d.C. (Aldunate 1993; Adán et al. 2016).

El complejo cultural Pitrén fue la primera ocupación agroalfarera del sur de Chile, cuya sucesora es El Vergel, complejo que se desarrolló en la zona donde habitaron los mapuches, quienes se enfrentaron al contacto hispánico (Aldunate 1993; Adán et al. 2016).

El complejo El Vergel ocupó las áreas entre el río BíoBío y aun el lago Llanquihue, y se asocia directamente con cerámicas de diversos tipos y formatos. Éstas se utilizaron como ataúdes para párvulos y adultos (Aldunate 1993) y, de acuerdo con Bullock (1970), se complementaban con tapas, elaboradas también de cerámica, para así cerrar las urnas.

Según Bullock (1970), muchos de los artefactos mortuorios encontrados en la Región de la Araucanía no se hallaron sino de manera fortuita, al realizar trabajos 


\section{nithe}

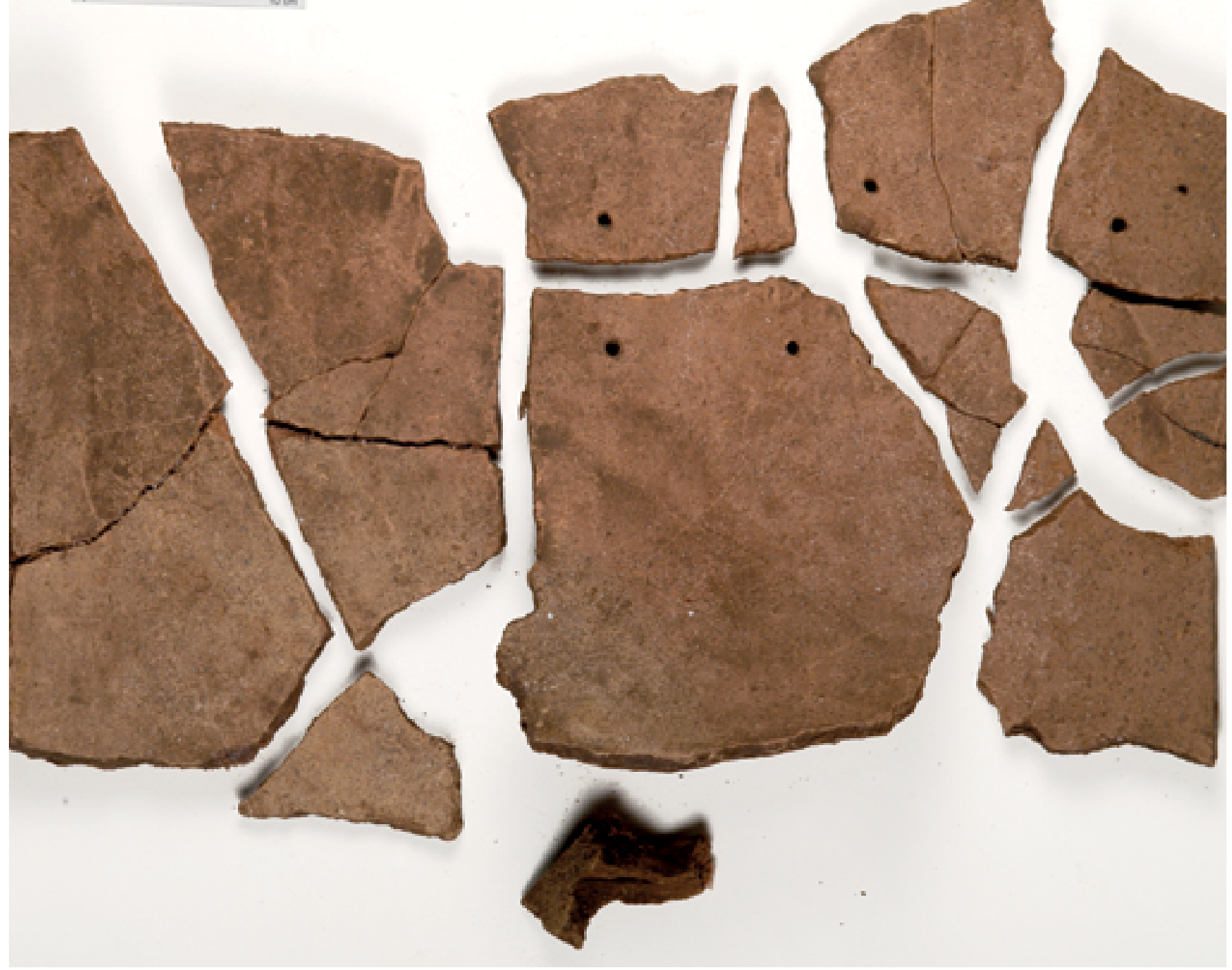

FIGURA 1. Estado inicial de fragmentos (Fotografía: Jacqueline Elgueta Ortega, 2012; cortesía: Archivo del Centro Nacional de Conservación y Restauración [CNCR], Chile).

agrícolas. A lo anterior se suma que en la época colonial se tenía por costumbre guardar monedas de plata en urnas y luego enterrarlas, por lo que, si alguien las encontraba, pensaba que podrían contener monedas, de manera que las sacaban y si no tenían nada en su interior, solamente las quebraban (cfr. Bullock 1970: 13).

En esta etapa de trabajo, los desafíos para intervenir la pieza se centraron en la escasez de antecedentes culturales y arqueológicos. Por otro lado, su levantamiento morfológico se dificultó a causa del bajo grado de completitud de la cerámica y de la imposibilidad de apoyar los fragmentos entre sí, a lo que se sumaron las grandes dimensiones de éstos. Por otra parte - decisión que comparte el museo-, las comunidades indígenas de la Región de la Araucanía no están de acuerdo con la exhibición de los objetos de carácter mortuorio en los museos. Esto implicó una reflexión en torno de si debían

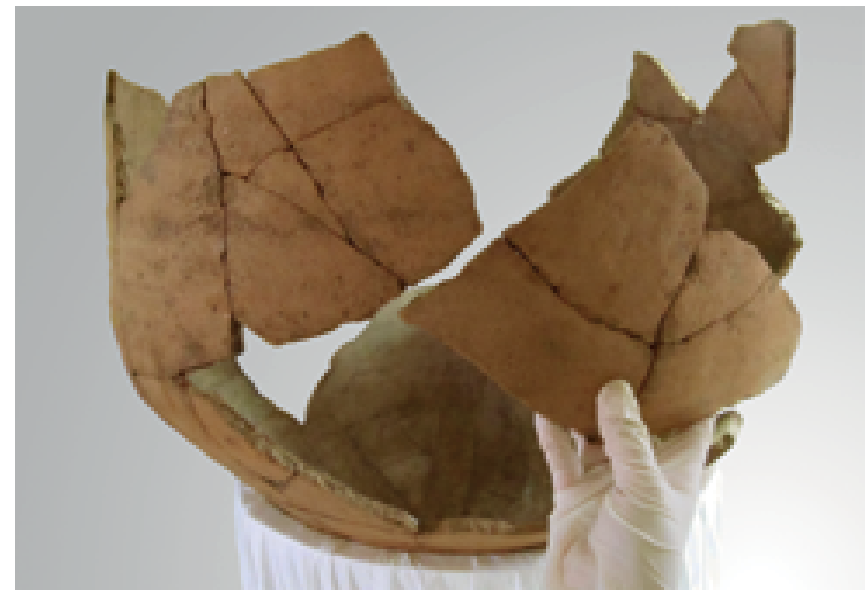

FIGURA 2. Vista de la base y fragmentos sin áreas de calce (Fotografía: Jacqueline Elgueta Ortega, 2012; cortesía: Archivo del Centro Nacional de Conservación y Restauración [CNCR], Chile). 


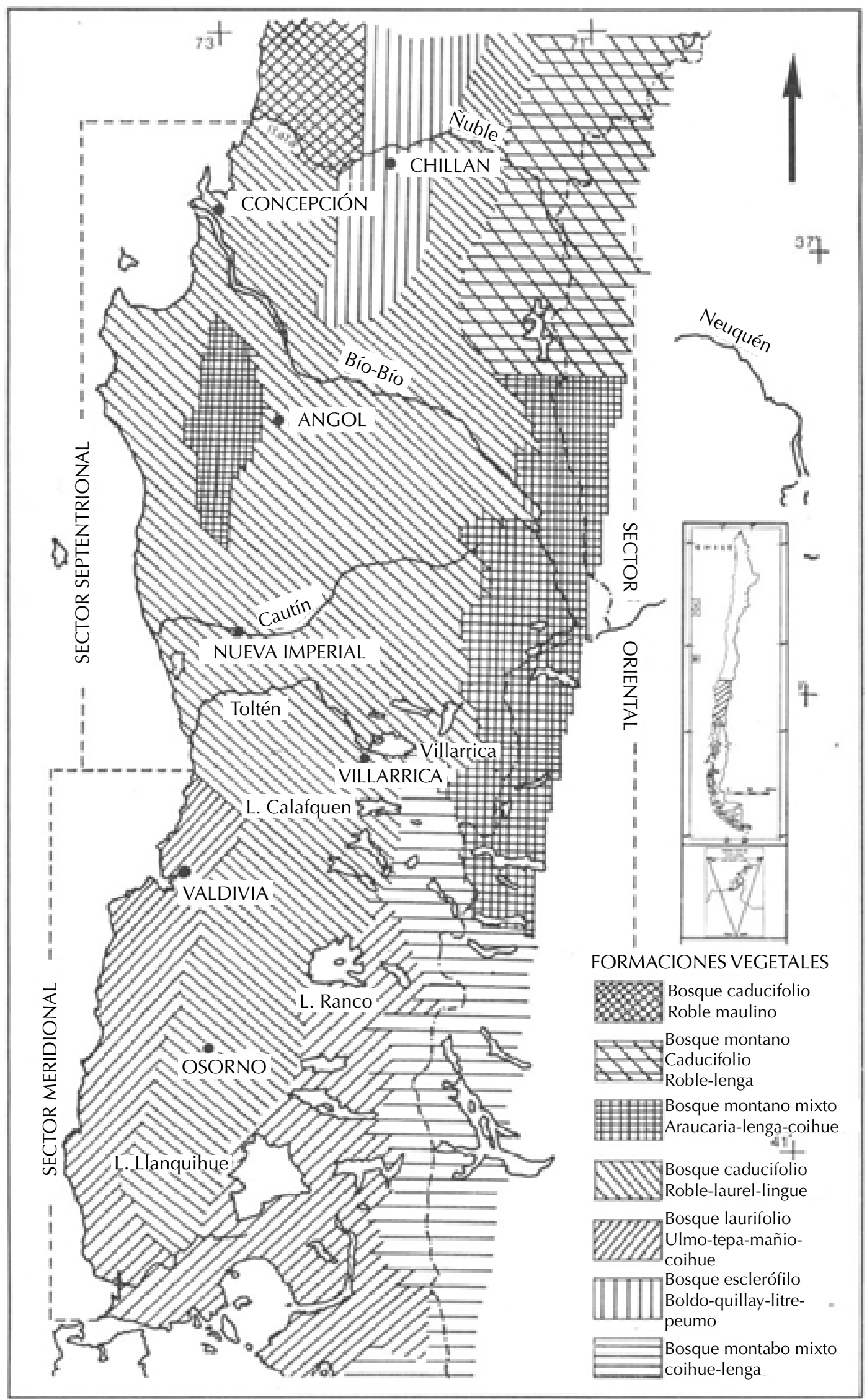

FIGURA 3. Nueva Imperial y Región de la Araucanía (Fuente: Aldunate 993: 331). 
o no utilizarse procedimientos de intervención para reconstruir la pieza, puesto que, si se procedía a su restauración, ésta ocuparía un espacio considerable en el depósito del museo. Por otro lado, la imposibilidad de intervenir la pieza dificultó reconocer sus datos objetuales, como son sus dimensiones y características morfológicas, por mencionar sólo dos de éstos.

Ante los problemas anteriores, el Laboratorio de Arqueología solicitó a la Unidad de Documentación Visual e Imagenología evaluar la factibilidad de reconstruir virtualmente la pieza a partir de los fragmentos individuales, lo que a su vez permitiría corroborar: a) el volumen y peso efectivo de fragmentos, $b$ ) el volumen y peso proyectado de toda la pieza, considerando un resane estructural hipotético, c) la forma y la tipología cerámicas, y d) la factibilidad de generar la propuesta de intervención.

\section{El procedimiento para el levantamiento tridimensional y análisis morfológico de la urna}

El CNCR (Centro Nacional de Conservación y Restauración, Chile) no contaba con la experiencia previa de un levantamiento tridimensional de un objeto patrimonial, por lo que para este primer desafío se utilizó una metodología constituida por tres etapas: la documentación volumétrica, la reconstrucción y restauración virtual, y su análisis computarizado.

Según la guía metodológica para digitalización de fragmentos manipulables del British Museum (Bevan et al. 2014), la estrategia general consiste en fotografiarlos uno por uno, repitiendo la captura en rotaciones e inversiones sucesivas hasta cubrir la totalidad de su superficie. Asimismo, la separación del fondo de la figura, y de ésta con su propia sombra, se abordó generando máscaras para cada fotografía, mientras que la gestión de color de las imágenes se resolvió mediante el uso de la tarjeta de calibración de color ColorChecker Passport@ y el pos-

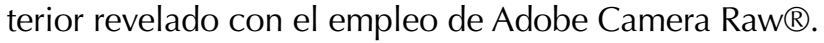

El procesamiento de las imágenes y la obtención de las nubes de puntos y mallas tridimensionales para cada fragmento se llevó a cabo con el software Agisoft Photoscan®: una vez capturados cada uno de éstos, se escalaron a su tamaño original y se exportaron como archivos separados en formato OBj y mapa de textura con formato PNG de 16 bits.

Luego se procedió a ubicar en el espacio cada uno de los fragmentos, proceso que se conoce como reconstrucción o anastilosis digital (Fabregat et al. 2012). Este paso metodológico se realizó con el software Blender $\mathbb{R}$ mediante la inserción de los fragmentos individuales en un sistema de coordenadas compartido, para lo que se utilizó un sistema de referencias externas que posibilitara correcciones y ediciones menores no destructivas tanto en la escala local de cada fragmento como en la escala global del objeto reconstruido (Figura 4a).
Posteriormente, la ubicación de los fragmentos que no estaban en contacto se proyectó considerando las curvaturas en ambos sentidos (curvatura lateral para ubicación en eje $Z$, curvatura horizontal para plano XY), además de los patrones de color y elementos inherentes a cada fragmento observables a simple vista.

El siguiente paso consistió en reconstruir la volumetría faltante, aquella correspondiente al espacio intersticial de los fragmentos físicos, generando así los denominados resanes virtuales. El procedimiento de restauración virtual adoptado se desarrolló por medio de un volumen teórico en torno del eje de revolución del conjunto reconstruido en el paso anterior, del cual se extrajeron los volúmenes correspondientes a los fragmentos originales (Figuras 4b-4d).

Finalmente, el modelo resultante se estudió en su globalidad con el fin de identificar sus características volumétricas, no sin dejar de observar de manera virtual la posibilidad de efectuar una reconstrucción física del conjunto.

Para explorar las características de la geometría, el modelo obtenido se sometió a diferentes estudios morfométricos para revelar información ya no sobre los fragmentos aislados, sino de la urna como un todo unitario. Se generaron vistas axiales de los cuatro ejes principales para obtener dimensiones absolutas y medidas sobre las características principales de la urna (alturas y diámetros de base, cuello y boca) (Figura 5), las que se complementaron con cortes y secciones sagitales sobre los mencionados ejes para revelar información sobre el espesor de la pasta y el grado de extensión de las áreas faltantes (Figura 6).

Asimismo, en busca de contrastar información sobre la compactación de la pasta que pudiera apoyar algunas de las hipótesis sobre el proceso de fabricación de la urna, se efectuó el cálculo del espesor local (Dougherty y Kunzelmann 2007; Barré-Brisebois 2011) con el software Blender ${ }^{\circledR}$ a lo largo de la geometría (Figura 7). En particular, se relacionaron las variaciones en el espesor de la geometría con la presunción de que la urna hubiese sido manufacturada con base en el sistema de rodetes.

En relación con los estudios estructurales, se implementaron dos escenarios de cálculo con la intención de simular la cohesión general del modelo intervenido y, así, aproximar el cálculo real de las fuerzas a las que se sometería.

El primer cálculo general se realizó considerando la urna restaurada como una unidad estructural indivisible, escenario ad hoc en aquellos casos en que una intervención de este tipo supone una fusión íntima entre las piezas originales y las nuevas, como en las intervenciones con yeso (las cuales se consideran extremadamente invasivas y se realizan si y sólo si la pieza tiene un riesgo de carácter estructural y no como una reconstrucción de tipo estético). De acuerdo con esta estrategia planteada, se espera que el comportamiento del conjunto resuelva de mejor manera los compromisos estructurales en las zonas intervenidas, por lo que la pregunta se traslada a conocer y determinar tanto las zonas en fragmentos 


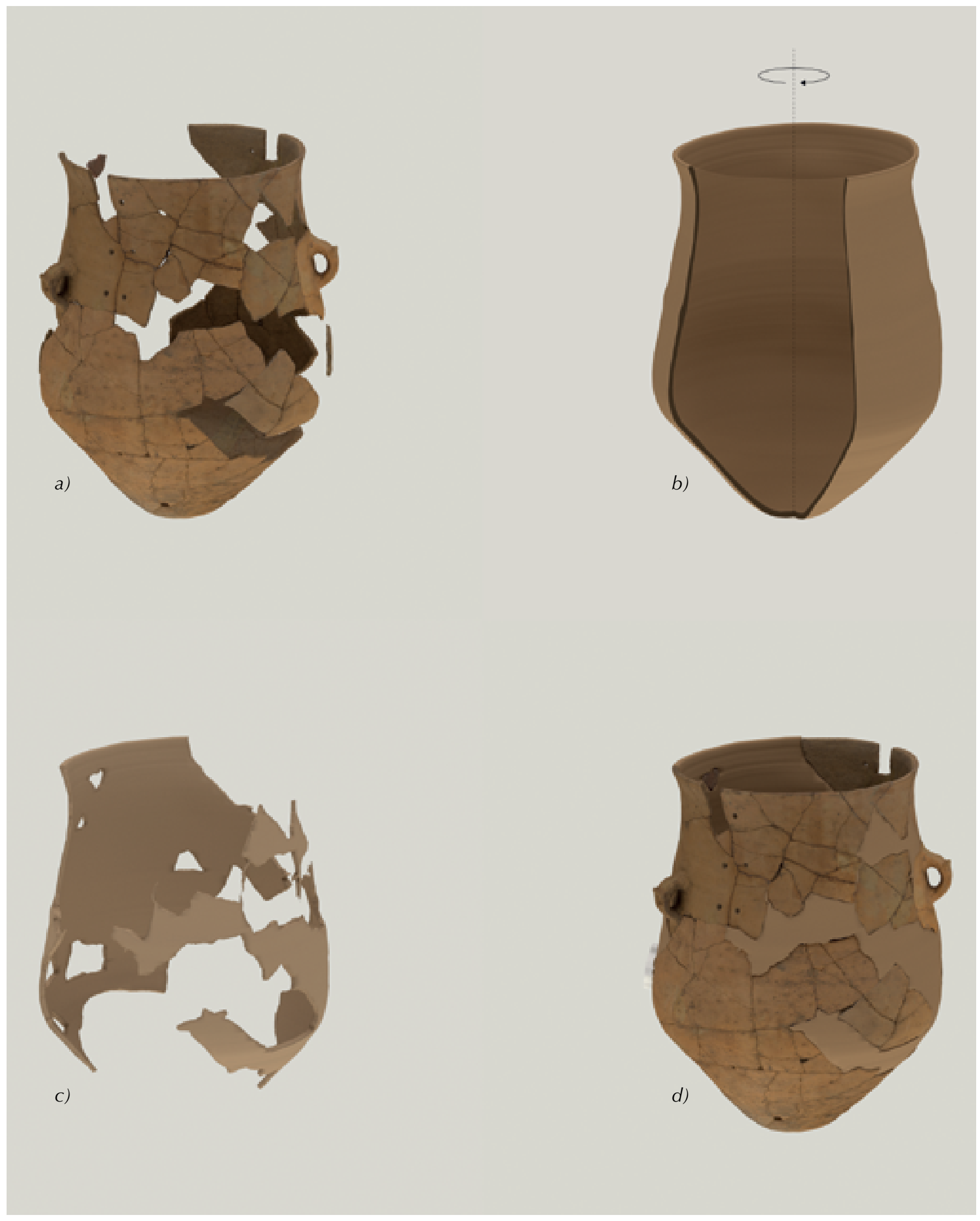

FIGURA 4. a) Reconstrucción piezas originales; b) Volumen teórico; c) Resanes extraídos por diferencia; d) Superposición y restauración final (Fotografía: Antonio Suazo Navia, 2015; cortesía: Archivo del Centro Nacional de Conservación y Restauración [CNCR], Chile). 

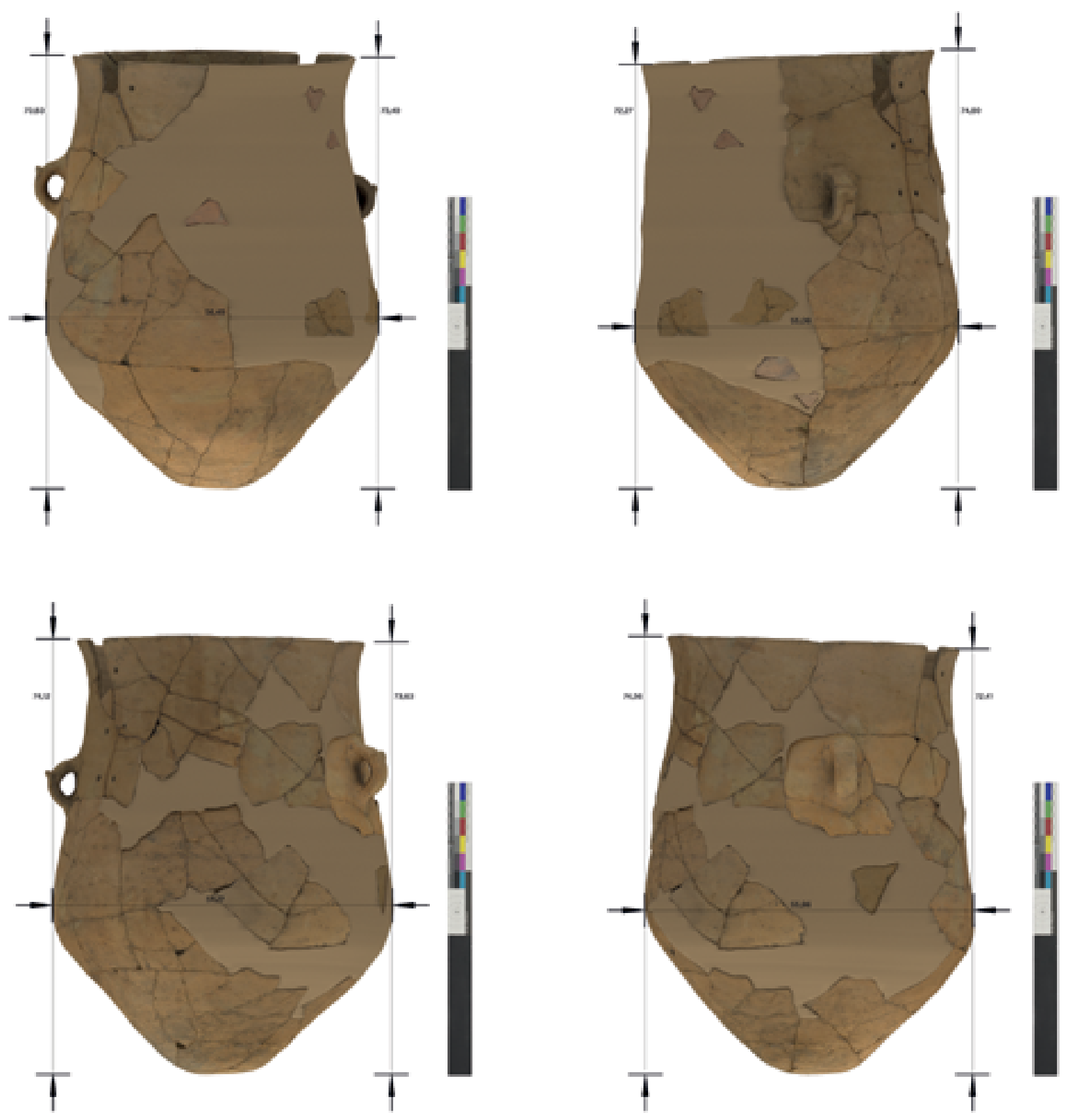

FIGURA 5. Vistas axiales y dimensiones generales de la urna (unidad de medida; centímetros, acompañada de una escala gráfica en la imagen) (Fotografía: Antonio Suazo Navia, 2015; cortesía: Archivo del Centro Nacional de Conservación y Restauración [CNCR], Chile).

originales, mejor preparadas para la solicitud estructural actual, como su ubicación y extensión.

Al desconocer las propiedades de resistencia de la pasta cerámica, el acercamiento a este primer escenario consideró: 1) la continuidad formal de su superficie y la distancia en cada vértice hasta el área que corresponde con el borde en contacto con otro fragmento, la zona donde se deposita el material nuevo con mejor resistencia, y 2) la altura del vértice respecto del total de la urna, información frecuentemente utilizada para estimar la compresión debida al propio peso del conjunto. La forma de aproximar el cálculo fue mediante un signed distance field (Park et al. 2010) con el software Blender ${ }^{2}$, considerando la ubicación en el eje $Z$, generado por vértice y almacenado en forma de imagen, reutilizando las coordenadas de textura de la información de color.

Se obtiene, así, una representación que muestra la ubicación y la extensión de las zonas del conjunto que ofrecerían una menor resistencia, principalmente aquéllas interiores de las piezas originales, las que reciben y acumulan todo el 

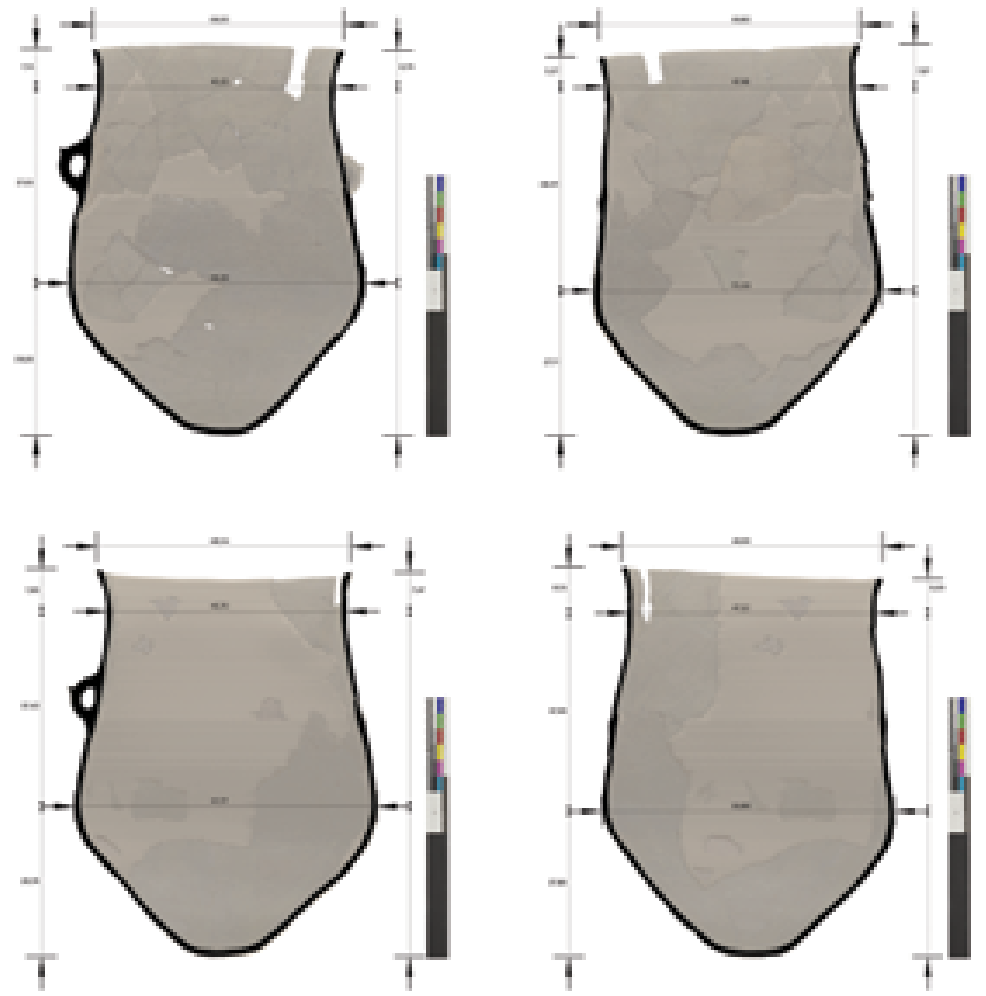

FIGURA 6. Secciones practicadas sobre los ejes principales (Fotografía: Antonio Suazo Navia, 2015; cortesía: Archivo del Centro Nacional de Conservación y Restauración [CNCR], Chile).

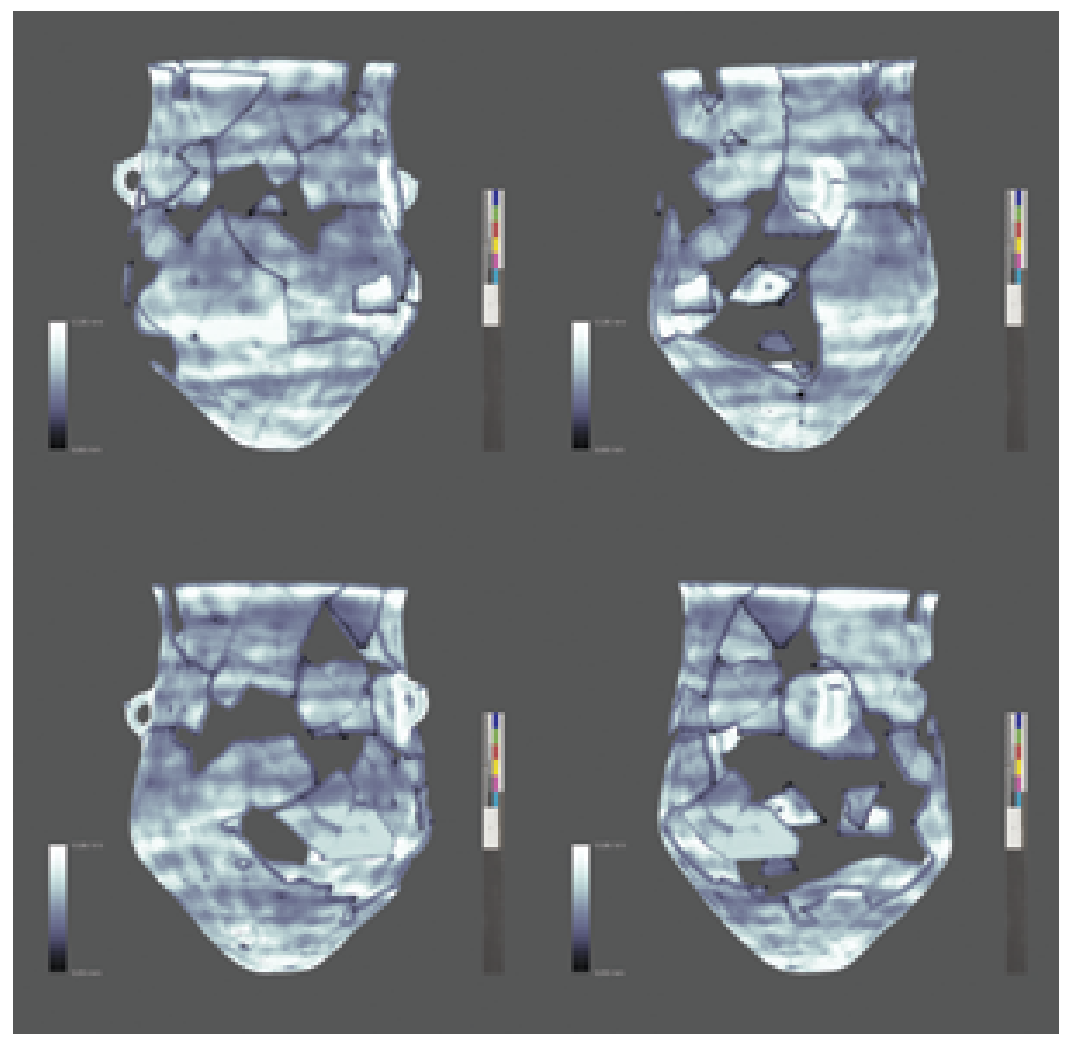

FIGURA 7. Cálculo de espesor local. Nótense los patrones horizontales (Fotografía: Antonio Suazo Navia, 2015; cortesía: Archivo del Centro Nacional de Conservación y Restauración [CNCR], Chile). 
compromiso estructural, no sólo de la estabilidad mecánica del conjunto sino también del propio peso muerto ${ }^{1}$ del total de los fragmentos y resanes reintegrados (Figura 8).

Un segundo cálculo —que se acerca a los criterios actuales de conservación utilizados en el Laboratorio de Arqueología - se efectuó tomando en cuenta los fragmentos individuales que actúan como un todo a través de uniones, enfoque más compatible con intervenciones contemporáneas, donde dicho criterio podría llevar a aplicar un material sintético de bajo protagonismo, como algunos plásticos o resinas adhesivas, únicamente en los bordes de contacto entre las piezas.

La manera de aproximarse al análisis fue mediante una simulación física, calculada con el software Blender ${ }^{\circledR}$, con los parámetros de masa de cada fragmento, peso específico de la pasta cerámica, aceleración de la gravedad y zonas de aplicación del adhesivo. Para estos efectos, el cálculo de la masa consideró los resanes como si se materializaran usando el mismo peso específico de la pasta cerámica original. ${ }^{2}$ De esta forma, los valores de peso específico, efectivos en los fragmentos originales y atribuidos en el caso de los resanes, se complementaron con las propiedades de 1) fricción y 2) factor de elasticidad, como forma de parametrizar la respuesta del adhesivo asociada con dichas superficies. La simulación física calculada ${ }^{3}$ se usó para estimar la posición y orientación de los fragmentos a lo largo de un rango de tiempo de 10 segundos, generando imágenes estáticas para intervalos de tiempo fijos que finalmente se unificaron en una imagen final. Ésta (Figura 9) muestra que las características tridimensionales de las uniones y los fragmentos (en particular, la forma en que se distribuye la masa en cada fragmento y la inercia mecánica del conjunto) no ofrecen la resistencia necesaria para que la urna intervenida conserve el estado de reposo, por lo que colapsa en su propio eje de torsión en los primeros segundos de simulación.

\section{Los resultados}

Respecto de las metas de documentación tridimensional y reconstrucción virtual, las metodologías aplicadas fue-

\footnotetext{
${ }^{1}$ Este fenómeno se aprecia notoriamente en el tramo inferior de la urna, visiblemente más sometido estructuralmente a la acumulación de los esfuerzos de compresión que ejerce sobre él el tramo superior. Al resultado en escala de grises se aplicó LUT de colores "Rainbow" para facilitar su lectura.

${ }^{2}$ Esto se derivó a partir de una tabla de pesos específicos de cada pieza, donde la relación entre el peso real medido en balanza digital y el volumen de aire obtenido por análisis tridimensional dentro de Blender ${ }^{\circledR}$ arrojó un valor promedio del peso específico de la pasta de $1838 \mathrm{~kg} / \mathrm{m}^{3}$. ${ }^{3}$ En el cálculo se utilizaron versiones "Convex Hull" de cada fragmento, considerando las piezas individuales con características de "cuerpo rígido", es decir, no deformable. A futuro, esta aproximación al cálculo podría extenderse para considerar modelos más elaborados para parametrizar el comportamiento de la pasta.
}

ron satisfactorias tanto en el registro de las características morfológicas de los fragmentos individuales como en la articulación del todo unitario. La posibilidad de estudiar los fragmentos no de manera individual sino a partir de la urna reconstruida, así como los estudios y los análisis morfométricos practicados, lograron en conjunto recuperar la información sobre las dimensiones generales, como alturas y diámetros, y generar vistas y secciones no apreciables en la realidad. Puede afirmarse, entonces, que los resultados del análisis del espesor local aportaron los datos necesarios para validar la hipótesis sobre el uso de rodetes para la manufactura de la urna.

Como consecuencia, la totalidad de los fragmentos pudieron ubicarse en el espacio, recuperándose el volumen correspondiente a las áreas desaparecidas, acción que no podía resolverse antes de contar con la reconstrucción fotogramétrica.

En relación con los análisis referidos a la posibilidad de intervenir directamente los fragmentos, la simulación en el primer cálculo evidencia que, si bien los resanes colaboran con la continuidad estructural necesaria, una parte importante de la fuerza se traslada hacia los fragmentos originales, que reciben y acumulan todo el compromiso estructural, esto es, no sólo de la estabilidad mecánica del conjunto sino también del propio peso muerto del total de los fragmentos. Derivado de esto, el análisis muestra que la integridad de la urna queda comprometida $y$, al cabo de un tiempo, puede colapsar por fatiga de material, dañando irreparablemente los fragmentos originales.

Asimismo, vale recalcar que, en el segundo análisis practicado, las características tridimensionales de las uniones y los fragmentos (en particular la forma en que se distribuye la masa en cada fragmento y la inercia mecánica del conjunto) no ofrecen la resistencia necesaria para que la urna intervenida conserve el estado de reposo, por lo que colapsa en su propio eje de torsión en los primeros segundos de simulación.

Como consecuencia de este segundo análisis, la interpretación de los valores sugiere que el área de contacto - y la forma en que ésta se distribuye en las superficies de cada fragmento - no es lo suficientemente amplia ni distribuida (desde el punto de vista de brindar la inercia necesaria) como para que descanse en ella la función principal de autosoportabilidad estructural del conjunto. De acuerdo con esto, la propuesta de intervención y reconstrucción física de la pieza debe prever un soporte auxiliar para evitar el colapso de los fragmentos.

\section{Conclusiones}

El trabajo desarrollado valida nuevamente las metodologías de digitalización tridimensional (Martínez et al. 2010; Fragoso 2015; Creaform, 2014; Jáidar et al. 2017), cuyas aplicaciones no se restringen a la documentación de un objeto y su registro. En este caso, la reconstrucción virtual dotó de un nuevo sentido a nuestro obje- 


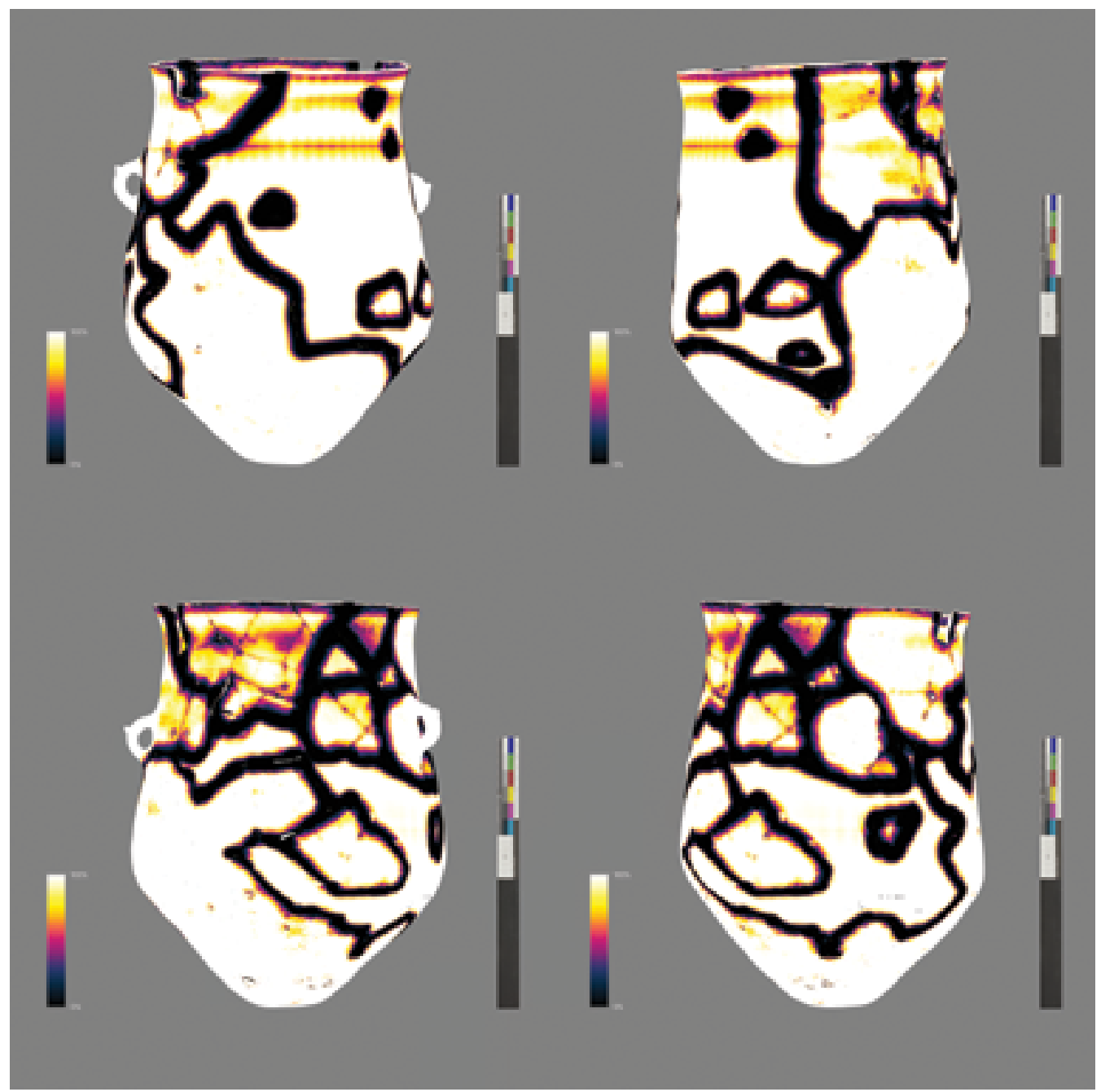

FIGURA 8. Primer análisis sobre continuidad y distancia hasta los bordes de cada fragmento. La barra de porcentaje (Fotografía: Antonio Suazo Navia, 2015; cortesía: Archivo del Centro Nacional de Conservación y Restauración [CNCR], Chile).

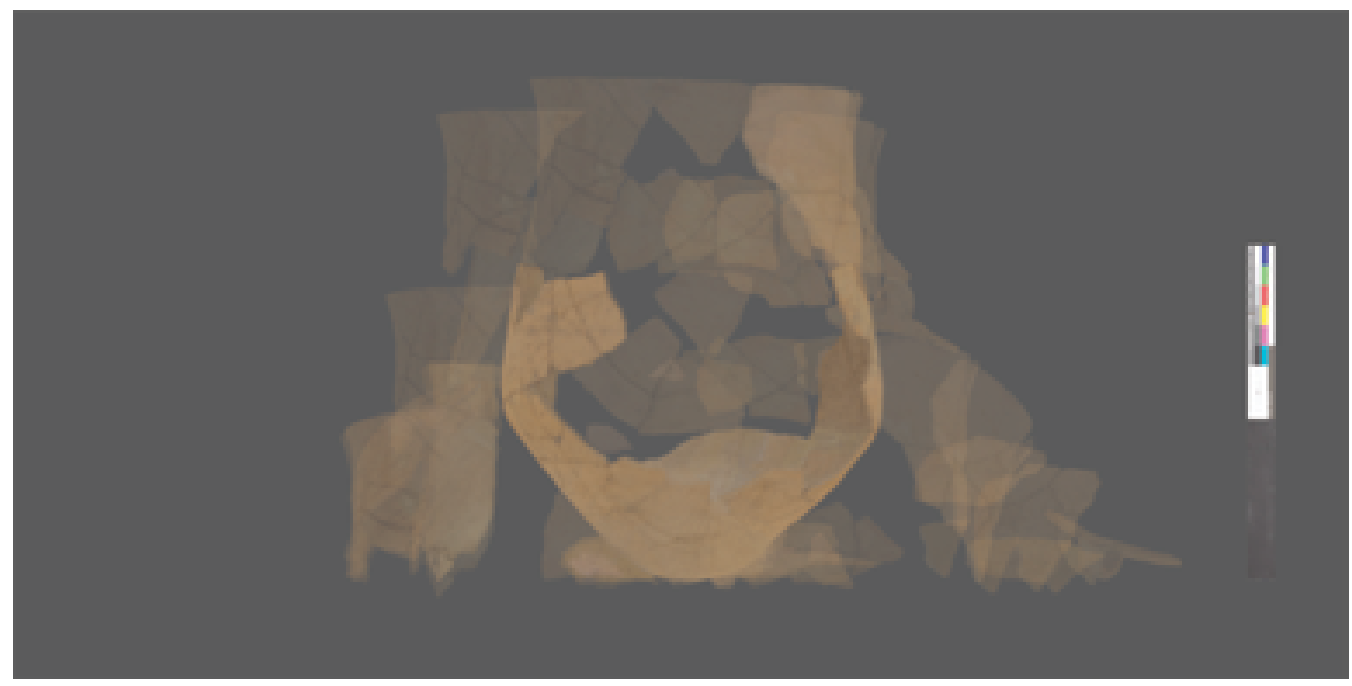

FIGURA 9. Segundo análisis, estabilidad del conjunto autosoportada en los cantos de los fragmentos originales (Fotografía: Antonio Suazo Navia, 2015; cortesía: Archivo del Centro Nacional de Conservación y Restauración [CNCR], Chile). 
to de estudio: a partir de los fragmentos logró reconstruirse la forma general de la urna.

De esta manera, se contribuye a la realización de estudios objetuales necesarios para el levantamiento de datos de las cerámicas arqueológicas, aportando información para conocer su proceso de manufactura y características objetuales como el peso, las dimensiones, las particularidades tecnológicas, la función y las proyecciones virtuales de las restauraciones hipotéticas, útiles para el conservador-restaurador, quien necesita dichos antecedentes para ofrecer explicaciones plausibles del estado de conservación de la pieza y proponer estrategias de intervención.

Los resultados obtenidos a partir de la digitalización por fotogrametría, reconstrucción virtual y análisis morfológico permitirán sugerir al museo propietario tres caminos para utilizar el modelado tridimensional: a) almacenar la urna, resolviendo la estabilidad mecánica del conjunto mediante un soporte complementario; $b$ ) generar una réplica a tamaño real del conjunto reconstruido por medio de impresión digital 3D, y c) difundir la pieza a través de medios digitales con una propuesta museográfica acorde (pantalla touch, proyección data-show, entre otros).

Las nuevas opciones generadas para los procesos de intervención sobre la urnas nos hacen reflexionar respecto de los desafíos de los restauradores cuando deben abordar temáticas vinculadas con la exposición de restos humanos y sus objetos fúnebres asociados, donde las posiciones a favor o en contra son variadas (véanse Ordóñez 2014; Gazi, 2014), pero que, en este caso de estudio, se consideró la voluntad de las comunidades de no exhibir las urnas mortuorias, lo que nos condujo a cuestionarnos sobre el tipo de intervención por el que se optará.

El tamaño de la pieza calculado según la reconstrucción virtual corrobora que dentro de su espacio interior es muy probable que se hayan depositado restos humanos. A pesar de carecer de estudios contextuales, se presume que la fragmentación podría vincularse con las creencias coloniales mencionadas más arriba por Bullock (1970) o por presión del sedimento durante el contexto de enterramiento que provocó las fracturas.

Como comentario adicional, en comparación con otras técnicas de captura, como láser escáner, luz estructurada o hand-held, se constató la importancia de utilizar el flujo fotogramétrico para recuperar la información de color, que fue el principal dato para ensamblar y articular los fragmentos en un todo unitario.

Finalmente, es necesario destacar que la metodología escogida puede considerarse una aproximación al estudio de los factores relacionados con el comportamiento estructural, no así con un análisis que aproveche la descripción geométrica tridimensional de la pieza para evaluar las deformaciones y traspasos de energía (como el análisis de elementos finitos FEM) ${ }_{1}^{4}$ que poco a poco la

\footnotetext{
${ }^{4}$ El método de elementos finitos en el cual se basa el análisis FEM permite
} efectuar ensayos al equilibrio, esfuerzos y desplazamientos en sistemas literatura comienza a insinuar (Guarneri et al. 2017). A futuro, esta aproximación podría extenderse para considerar una escala menor, como la composición del material, y evaluar la cohesión de la pasta cerámica entre sus distintos componentes (arcilla, antiplásticos, etc.), integrando estas variables al análisis estructural.

Del trabajo presentado se destaca que la técnica empleada permite al restaurador enfrentarse a un caso en el que la descontextualización arqueológica y la discontinuidad morfológica dificultan el estudio de la pieza, donde la reconstrucción virtual por fotogrametría aporta los datos esenciales para la interpretación de estos antecedentes, relevantes para la evaluación crítica del estado de conservación y la toma de decisiones de intervención de un objeto.

\section{Referencias}

Adán, Leonor, Rodrigo Mera, Ximena Navarro, Roberto Campbell, Daniel Quiroz, y Marco Sánchez

2016 “Historia prehispánica en la región centro-sur de Chile: cazadores recolectores holocénicos y comunidades alfareras (ca. 100000 años a.C. a 1550 años d.C)", en Fernanda Falabella, Mauricio Uribe, Lorena Sanhueza, Carlos Aldunate y Jorge Hidalgo (eds.), Prehistoria en Chile. Desde sus primeros habitantes hasta los incas, Santiago de Chile, Universitaria, pp. 401-441.

Aldunate del S., Carlos

1993 [1986] "Estadio alfarero en el sur de Chile (500 a ca. 1800 d.C)", en Jorge Hidalgo, Virgilio Schiappacasse, Hans Niemeyer, Carlos Aldunate e Iván Solimano (eds.), Prehistoria: desde sus orígenes hasta los albores de la conquista, Santiago de Chile, Alfabeta, pp. 329-348.

Anón.

2008 "Asesorías, proyectos, investigaciones, cursos y publicaciones 2007", Conserva, 12: 111-155.

2009 "Asesorías, proyectos, investigaciones, cursos y publicaciones 2008", Conserva, 13: 123-159.

Barré-Brisebois, Colin

2011 "Approximating Translucency for a Fast Cheap and Convincing Subsurface Scattering Look", GDC, documento electrónico disponible en [https://colinbarrebrisebois.com/2011/03/07/ gdc-2011-approximating-translucency-for-a-fast-cheap-andconvincing-subsurface-scattering-look], consultado en agosto de 2017.

Bevan, Andrew, Robert Kaleta, Chiara Boncacchi, y Adi KeinanSchoonbaert

2014 Photo-Masking for 3D Models of Artefacts. MicroPasts Technical Note 2, Londres, The British Museum.

Bullock, Dillman

1970 La cultura kofkeche, Santiago de Chile, Museo Dillman S. Bullock.

mecánicos que tradicionalmente se han aplicado al análisis de fuerzas en las industrias aeroespacial, aeronáutica y automotriz, entre otras. 
Correa Orozco, Carolina, Pía Monteverde Puig, Lorena Ormeño Bustos, y Antonio Suazo Navia

2016 "Preservación de la información mediante herramientas de virtualización: fotogrametría y panorámicas de alta resolución", Conserva, 21: 135-144.

Creaform

2014 An Introduction to 3D Scanning, documento electrónico disponible en [https://www.creaform3d.com/en/introduction-3d-scanning], consultado en agosto de 2017.

Dougherty, Robert, y Karl-Heinz Kunzelmann

2007 "Computing Local Thickness of 3D Structures with ImageJ", Microscopy and Microanalysis, 13 (S02): 1678-1679.

Fabregat Bolufer, Daniel Tejerina Antón, Jaime Molina Vidal, y

Carolina Frías

2012 "Anastilosis virtual con Blender: las Termas del Yacimiento Villa Romana De L'albir", Virtual Archaeology Review, 3 (6): 45.

Fragoso Calderas, Irlanda

2015 "El uso del escáner 3D en la CNCPC. Restos y perspectivas a futuro", Conservación y Restauración, 6: 40-44, documento electrónico disponible en [http://conservacion.inah.gob.mx/ publicaciones/?p=1301], consultado en julio de 2017.

Gándara Vázquez, Manuel 2016 “¿Difundir o divulgar? He ahí el dilema”, en D. JiménezBadillo y M. Gándara Vázquez (eds.), El patrimonio cultural y las tecnologías digitales. Experiencias recientes desde México, México, Instituto Nacional de Antropología e Historia/Consejo Nacional de Ciencia y Tecnología, pp. 60-73.

Gartstki, Keni

2017 "Virtual Representation: The Production of Digital Artifacts", Journal of Archaeological Method and Theory, 24 (3): 726-750.

Gazi, Andromache

2014 "Exhibition Ethics-an Overview of Major Issues", Journal of Conservation and Studies, 12 (1): 1-10.

Guarneri, Alberto, Francesca Fissore, Andrea Masiero, y Antonio Vettore

2017 "From Survey to FEM Analysis for Documentation of Built Heritage: The Case Study of Villa Revedin-Bolasco", International Archives of the Photogrammetry, Remote Sensing and Spatial Information Sciences, 42 (5): 527-533.
IFVA

2012 Los principios de Sevilla: Principios internacionales de la arqueología virtual, International Forum for Virtual Archaeology (IFVA), documento electrónico disponible en [http:// smartheritage.com/wp-content/uploads/2016/06/PRINCIPIOS-DE-SEVILLA.pdf], consultado en marzo de 2017.

Jáidar Benavides, Yareli, María Fernanda López Armenta, Celedonio Rodríguez Vidal, Isabel Villaseñor, Ana Jose Ruigómez Correa, e Irlanda Stefanie Fragoso Calderas

2017 "Digitalización tridimensional para la documentación, análisis y conservación de bienes culturales: los relieves decorativos en piedra de la zona arqueológica de Tula, Hidalgo, México", Intervención, 8 (16): 43-56.

Martínez Carillo, Ana, Arturo Ruiz Rodríguez, y Miguel Ángel Rubio Paramio

2010 "Digitalización y visualización 3D de cerámica arqueológica", Virtual Archaeology Review, 2 (1): 133-136.

Ordóñez, María

2014 "A Museumand its Mummies. The Rijksmusemun VoIkenkunde Stand on Human Remains and the View of is Personnel", tesis para la especialización en estudios de museo, Facultad de Arqueología, Leiden, Universidad de Leiden.

Park, Taejung, Sung-Ho Lee, Jong-Hyun Kim, y Chang-Hun Kim 2010 "CUDA-based Signed Distance Field Calculation for Adaptive Grids", en $10^{\text {th }}$ IEEE International Conference on Computer and Information Technology, 1202-1006, documento electrónico disponible en [https://www.researchgate.net/publication/221194166_CUDA-based_Signed_Distance_Field_Calculation_for_Adaptive_Grids], consultado en agosto de 2017.

Sánchez Climent, Álvaro, y María Luisa Cerdeño Serrano 2014 "Propuesta metodológica para el estudio volumétrico de cerámica arqueológica a través de programas free-software de edición 3D: el caso de las necrópolis celtibéricas del área meseteña", Virtual Archaeology Review, 11 (5): 20-33.

Stanco, Filippo, Sebastiano Battiato, y Giovanni Gallo 2011 Digital Imaging for Cultural Heritage Preservation: Analysis, Restoration, and Reconstruction of Ancient Artworks, Boca Raton, Taylor \& Francis Group.

Sopena Vicién, María Cruz 2006 "La investigación arqueológica a partir del dibujo informatizado en cerámica", Salduien, 6: 13-27. 


\section{Natalia Andrea Naranjo Mogollones}

Laboratorio de Arqueología,

Centro Nacional de Conservación y Restauración (CNCR), Chile natalia.naranjo@cncr.cl

Conservadora y restauradora de bienes culturales (Universidad Internacional [SEK, Chile]); actualmente cursa un magíster en filosofía de la ciencia (Universidad de Santiago de Chile) y se desempeña como conservadora del Laboratorio de Arqueología del Centro Nacional de Conservación y Restauración (CNCR, Chile), donde tiene como labor coordinar las diferentes líneas de trabajo que se desarrollan. Sus áreas de especialización son los procesos de alteración de la cerámica arqueológica y el manejo de colecciones patrimoniales.

\author{
Antonio Suazo Navia \\ Unidad de Documentación Visual e Imagenología, \\ Centro Nacional de Conservación y Restauración (CNCR), Chile \\ documentacion.4@cncr.cl
}

Arquitecto (Universidad de Chile) y magíster (c) en Patrimonio Cultural (Universidad Católica de Chile). Arquitecto (Universidad de Chile) con especialización de postítulo Introducción a la fotogrametría digital y su uso en patrimonio (Universidad de Burgos, España). Actualmente cursa el magíster en patrimonio cultural (Universidad Católica de Chile). Se desempeña en la Unidad de Documentación Visual e Imagenología como analista en actividades del Programa de Documentación Volumétrica. Sus áreas de especialización son la implementación de metodologías de análisis tridimensional y de reconstrucción virtual vía desarrollo de código.

Postulado/Submitted: 18.09.2017

Aceptado/Accepted: 11.04.2018

Publicado/Published: 15.08.2018 